\title{
Preparing the Health Workforce in Ethiopia: A Cross-sectional Study of Competence of Anesthesia Graduating Students
}

\author{
Sharon Kibwana ${ }^{1}$, Damtew Woldemariam ${ }^{1}$, Awoke Misganaw ${ }^{1}$, Mihereteab Teshome ${ }^{1}$, \\ Leulayehu Akalu², Adrienne Kols ${ }^{3}$, Young Mi Kim³, Samuel Mengistu', Jos van Roosmalen ${ }^{4}$, \\ Jelle Stekelenburg ${ }^{5}$
}

${ }^{1}$ Jhpiego, An affiliate of Johns Hopkins University, ${ }^{2}$ Ethiopian Association of Anesthetists, Addis Ababa, Ethiopia, ${ }^{3} \mathrm{Jhpiego}$, An affiliate of Johns Hopkins University, Maryland, USA, ${ }^{4}$ Vrije Universiteit, Amsterdam, ${ }^{5}$ Department of Obstetrics and Gynecology, Leeuwarden Medical Centre, Leeuwarden, Department of Health Sciences, Global Health, University Medical Centre Groningen/University of Groningen, Groningen, The Netherlands

\begin{abstract}
Background: Efforts to address shortages of health workers in low-resource settings have focused on rapidly increasing the number of higher education programs for health workers. This study examines selected competencies achieved by graduating Bachelor of Science and nurse anesthetist students in Ethiopia, a country facing a critical shortage of anesthesia professionals. Methods: The study, conducted in June and July 2013, assessed skills and knowledge of 122 students graduating from anesthetist training programs at six public universities and colleges in Ethiopia; these students comprise $80 \%$ of graduates from these institutions in the 2013 academic year. Data was collected from direct observations of student performance, using an objective structured clinical examination approach, and from structured interviews regarding the adequacy of the learning environment. Results: Student performance varied, with mean percentage scores highest for spinal anesthesia (80\%), neonatal resuscitation (74\%), endotracheal intubation (73\%), and laryngeal mask airway insertion check (71\%). Average scores were lowest for routine anesthesia machine check (37\%) and preoperative screening assessment (48\%). Male graduates outscored female graduates $(63.2 \%$ versus $56.9 \%, P=0.014)$, and university graduates outscored regional health science college graduates $(64.5 \%$ versus $55.5 \%, P=0.023$ ). Multivariate linear regression found that competence was associated with being male and attending a university training program. Less than $10 \%$ of the students believed that skills labs had adequate staff and resources, and only $57.4 \%$ had performed at least 200 endotracheal intubations at clinical practicum sites, as required by national standards. Discussion: Ethiopia has successfully expanded higher education for anesthetists, but a focus on quality of training and assessment of learners is required to ensure that graduates have mastered basic skills and are able to offer safe services.
\end{abstract}

Keywords: Anesthesia, ethiopia, higher education, objective structured clinical examination, student competency

\section{Background}

Despite significant advances in the provision of safe anesthesia in high-income countries, ${ }^{[1,2]}$ anesthesia-related

\begin{tabular}{|l|l|}
\hline \multicolumn{2}{|c|}{ Access this article online } \\
\hline Quick Response Code: & Website: \\
\hline & www.educationforhealth.net \\
\cline { 2 - 2 } & \\
\hline
\end{tabular}

Address for correspondence:

Sharon Kibwana, Johns Hopkins University, Kirkos Subcity, Kebele 02/03, House 693, Wollo Sefer, Addis Ababa, Ethiopia.

E-mail: sharon.kibwana@jhpiego.org and perioperative mortality in low-resource settings remains high, ${ }^{[3,4]}$ exacerbated by a critical shortage of anesthesia providers. ${ }^{[5]}$ Estimates suggest that in Ethiopia only 19 anesthesiologists (medical specialists with $9+$ years of university training), and 239 anesthetists (a mid-level cadre with 4 years of university training or nurses trained for 1 year) serve a country of approximately 80 million people..$^{[6,7]}$ Not only is the ratio of anesthesiologists to population in

This is an open access article distributed under the terms of the Creative Commons Attribution-NonCommercial-ShareAlike 3.0 License, which allows others to remix, tweak, and build upon the work non-commercially, as long as the author is credited and the new creations are licensed under the identical terms.

For reprints contact: reprints@medknow.com

How to cite this article: Kibwana S, Woldemariam D, Misganaw A, Teshome M, Akalu L, Kols A, et al. Preparing the health workforce in Ethiopia: A Cross-sectional study of competence of anesthesia graduating students. Educ Health 2016;29:3-9. 
Ethiopia among the lowest in the world, ${ }^{[8]}$ a survey ${ }^{[9]}$ of nurse anesthetists in Ethiopia found that only $62 \%$ could provide safe anesthesia and only $11 \%$ could provide obstetric anesthesia (as determined by a tool developed by Hodges et al. ${ }^{[10]}$ to help countries assess the state of anesthetic provision).

Many countries are training mid-level cadres in anesthesia to increase service coverage, ${ }^{[11-13]}$ but their education and supervision are often under-resourced and their work environments can be challenging. ${ }^{[14,15]}$ In Ethiopia, rapid expansion of training institutions to meet the great demand for health workers ${ }^{[7]}$ has put added stress on anesthesia education, with faculty, equipment, and infrastructure in short supply. ${ }^{[16]}$ This study examines competencies achieved by graduating anesthetist students in Ethiopia. It asks: (1) Are graduating students competent to practice safe anesthesia as defined in the national curriculum and guidelines? (2) What characteristics of students and training institutions are associated with achieving selected competencies in anesthesia? (3) What are students' perceptions of the adequacy of their learning environment?

\section{Methods}

\section{Study design and sample}

Findings come from baseline data collected as part of a study to evaluate the impact of interventions to improve the quality of education at anesthetist training programs in Ethiopia. All public higher education institutions that graduated students from anesthetist programs in 2013 were eligible for this study. Four universities and six regional health science colleges (RHSCs) met these criteria. (Universities offer a four-year anesthetist training program leading to a bachelor of science degree, while RHSCs offer a one-year diploma program in anesthesia for nurses who have at least two years of work experience). Students at four RHSCs had already graduated when data were collected. Therefore, the study sample is limited to four universities and two RHSCs, representing 6 of Ethiopia's 11 regions. All 153 anesthetist students who graduated from these institutions in 2013 were invited to participate in the study, but 31 had either returned home or did not wish to participate. Thus, the study includes 122 students, representing $80 \%$ of graduates.

\section{Measures and instruments}

Data come from direct observations of students' knowledge and skills in a simulated setting and structured interviews with students. Competencies to be assessed were selected based on national curricula and guidelines and international nurse anesthetist educational standards, ${ }^{[17]}$ as well as logistic considerations.

The objective structured clinical examination (OSCE) approach was used because it is a robust method for assessing clinical competence ${ }^{[18,19]}$ and is used by Ethiopian training institutions. There were 10 OSCE stations. At six stations, students were observed performing a skill on a mannequin or standardized patient. These stations covered (1) endotracheal intubation; (2) preoperative screening assessment and determination of appropriate anesthesia for the client, including history taking and interpersonal communication; (3) chest examination; (4) neonatal resuscitation; (5) cardiopulmonary resuscitation; and (6) laryngeal mask airway insertion check. At four stations, students were asked to describe or write down the steps they would take to effectively complete a procedure. These stations covered (1) lumbar puncture for spinal anesthesia; (2) the anesthesia work station, including a routine check of an anesthesia machine that students had used during clinical practicums; (3) considerations before and during blood transfusion; and (4) interpretation and management of postoperative complications. For each item on the OSCE checklist, observers responded "yes" (indicating that the item was performed correctly) or "no" (indicating that the item was performed incorrectly or not performed).

Structured interview tools collected student socio-demographic information and posed 12 questions about their experience in the classroom, skills lab, and clinical practicum. Students could respond "yes," "partially," or "no." Students were also asked how many endotracheal intubations they had performed under supervision.

\section{Data collection}

Twelve university instructors were recruited to observe and interview the students; all were trained anesthetists with expertise in skills assessments. They attended five days of training, during which they pre-tested the tools and demonstrated their ability to perform OSCE assessments by completing role plays and knowledge tests. To minimize bias, data collectors were assigned to institutions where they were not currently serving as faculty.

Data were collected in June and July 2013, after students had completed their final examinations. The data collection team spent two days, on average, at each training institution. Two co-investigators supervised data collection, verifying that data collectors were recording data appropriately; they did not interfere with the assessment.

Students rotated through each OSCE station, read a case scenario, and then either performed the required skill or described how they would address the scenario. The stations assessed clinical decision-making, communication, and psychomotor skills. The data collector assigned to each station completed a 6- to 16-item checklist while observing each student. Two other data collectors interviewed students after they completed the OSCE. On average, it took 10 minutes for a student to complete each OSCE station and 15 minutes for the interview. 
Kibwana, et al:: Competence of anesthesia graduating students in Ethiopia

\section{Data analysis}

Double data entry and cleaning were conducted using CSPro 5.0. Statistical analysis was performed using STATA version 13.1 software. Assumptions regarding normal distributions and outliers were checked before applying statistical analysis. Composite scores were calculated for each OSCE station; they are the mean percentage of items performed correctly at that station. The overall mean skills score was calculated as the sum of all OSCE station scores divided by the number of stations; hence, each station contributes equally to the overall score. Bivariate and multivariable linear regressions were conducted to identify factors predicting student competence. The dependent variable was the overall mean skills score, and the potential predictor variables in the regression analysis were gender, age, type of training institution, and whether the number of endotracheal intubations performed by each student (self-reported) was at least 200. Student interview responses were divided into two categories ("yes" and "no") for analysis; responses of "partially adequate/sufficient" were recoded as "no" responses. Since data showed clustering at the level of the schools, bivariate and multivariable regression analyses were performed for independent variables of interest with adjustment for clustering due to study design. Clustering was accounted for by the use of Huber-White (also called Sandwich or robust) standard errors. In the null model, the variations accounted for between institutions was $38.2 \%$ (intraclass correlation coefficient $=0.382$, with $95 \%$ $\mathrm{CI}=(0.055,0.709))$.

\section{Ethical considerations}

The study protocol was approved by the Johns Hopkins School of Public Health Institutional Review Board (IRB \#5051). Informed oral consent was obtained from all participants after the aim of the study was explained, and steps were taken to preserve the confidentiality of the information gathered.

\section{Results}

\section{Characteristics of study participants}

Most study participants were male (72.1\%), age 20-24 years (64.7\%), and from an urban area (62.3\%) [Table 1]. Few had prior job experience related to anesthesia (4.9\%), and most attended from university programs (66.4\%).

\section{Student competence on selected skills}

Higher education institutions in the country use $60 \%$ as the cut-off score for competency exams - we considered this as a threshold to judge student competence. The overall mean skills score across all OSCE stations was 61.5\% [Figure 1]. Student competence varied across stations, with mean scores highest for spinal anesthesia (79.5\%), followed by neonatal resuscitation (74.4\%), endotracheal intubation (72.8\%), and laryngeal mask airway insertion check (71.1\%). Average scores

\begin{tabular}{|c|c|c|c|c|}
\hline \multicolumn{5}{|c|}{$\begin{array}{l}\text { Table 1: Distribution of study participants by training } \\
\text { institution (percentages) }\end{array}$} \\
\hline \multirow[t]{2}{*}{ Characteristic } & \multicolumn{4}{|c|}{ Training institution } \\
\hline & $\begin{array}{l}\text { All students } \\
(n=122)\end{array}$ & $\begin{array}{c}\text { University } \\
(n=81,66.4 \%)\end{array}$ & $\begin{array}{c}\text { RHSC } \\
(n=41,33.6 \%)\end{array}$ & $P^{*}$ \\
\hline Gender & & & & 0.584 \\
\hline Male & 72.1 & 69.1 & 78.1 & \\
\hline Female & 27.9 & 30.9 & 21.9 & \\
\hline Age in years & & & & $<0.001$ \\
\hline $20-24$ & 64.7 & 88.9 & 17.1 & \\
\hline $25-30$ & 35.3 & 11.1 & 82.9 & \\
\hline Hometown & & & & 0.686 \\
\hline Urban & 62.3 & 64.2 & 58.5 & \\
\hline Rural & 37.7 & 35.8 & 41.5 & \\
\hline $\begin{array}{l}\text { Previous job experience } \\
\text { related to anesthesia }\end{array}$ & & & & 0.986 \\
\hline Yes & 4.9 & 4.9 & 4.9 & \\
\hline No & 95.1 & 95.1 & 95.1 & \\
\hline
\end{tabular}

${ }^{\star} P$ values are based on Pearson Chi-square tests adjusted for clustering. RHSC=Regional health science college

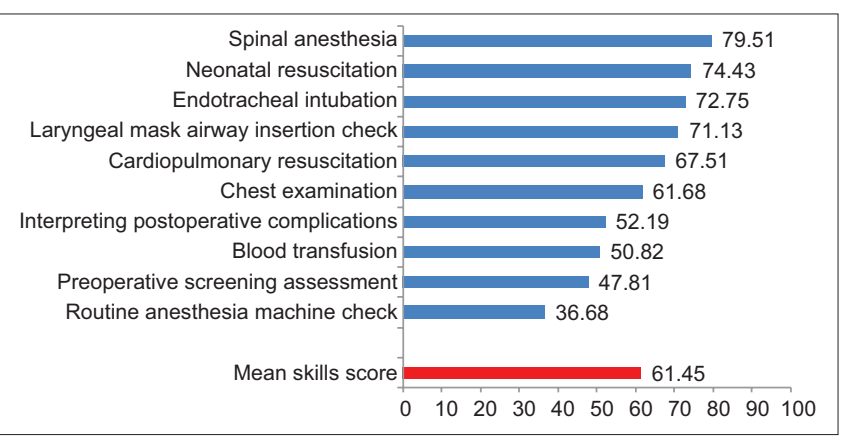

Figure 1: Mean percentage scores of anesthesia graduates, by OSCE station

were lowest for the routine anesthesia machine check (36.7\%) and preoperative screening assessment (47.8\%).

University graduates significantly outscored RHSC graduates overall (64.5\% versus $55.5 \%, P=0.023)$ and on two skills: Blood transfusion and laryngeal mask airway insertion check [Table 2]. RHSC graduates did not score significantly higher than university graduates on any skill.

Male graduates significantly outscored female graduates overall (63.2\% versus $56.9 \%, P=0.014)$ and on two skills: Routine anesthesia machine check and interpretation of postoperative complications. There was no significant difference by gender on the remaining eight skills.

\section{Student perceptions of the learning environment}

Less than $10 \%$ of students believed that skills labs had adequate staff and resources [Table 3], but approximately half rated their instructors as effective (50.0\%) and fair (48.4\%). Students rated the clinical practicum highest, but only $55.7 \%$ thought they had received sufficient practical experience. 
Kibwana, et al:: Competence of anesthesia graduating students in Ethiopia

\begin{tabular}{|c|c|c|c|c|c|c|c|}
\hline \multirow[t]{2}{*}{ OSCE station } & \multirow[t]{2}{*}{ Number of items } & \multicolumn{3}{|c|}{ Training institution } & \multicolumn{3}{|c|}{ Gender } \\
\hline & & University $(n=81)$ & $\operatorname{RHSC}(n=41)$ & $P$ & Male $(n=88)$ & Female $(n=34)$ & $P$ \\
\hline Spinal anesthesia & 10 & 78.9 & 80.7 & 0.589 & 78.9 & 81.2 & 0.609 \\
\hline Neonatal resuscitation & 10 & 75.3 & 78.7 & 0.761 & 75.5 & 71.8 & 0.439 \\
\hline Endotracheal intubation & 16 & 71.0 & 76.2 & 0.532 & 74.9 & 67.3 & 0.325 \\
\hline Laryngeal mask airway insertion check & 9 & 81.8 & 50.1 & 0.040 & 71.1 & 71.2 & 0.984 \\
\hline Cardiopulmonary resuscitation & 11 & 66.3 & 69.8 & 0.621 & 70.6 & 59.6 & 0.070 \\
\hline Chest examination & 12 & 65.2 & 54.7 & 0.205 & 65.8 & 51.0 & 0.063 \\
\hline Interpretation of postoperative complications & 6 & 55.6 & 45.5 & 0.061 & 54.4 & 46.6 & 0.001 \\
\hline Blood transfusion & 8 & 58.8 & 35.1 & $<0.001$ & 52.0 & 47.8 & 0.395 \\
\hline Preoperative screening assessment & 12 & 50.6 & 42.3 & 0.184 & 48.6 & 45.8 & 0.347 \\
\hline Routine anesthesia machine check & 12 & 41.4 & 27.4 & 0.185 & 40.5 & 26.7 & 0.027 \\
\hline Mean skills score* & & 64.5 & 55.5 & 0.023 & 63.2 & 56.9 & 0.014 \\
\hline
\end{tabular}

${ }^{*}$ The mean skills score is the sum of all OSCE stations divided by the number of stations; hence, each station contributes equally to the score. OSCE=Objective structured clinical examination, RHSC=Regional health science college

\section{Table 3: Perceptions of the learning environment, by student training institution and gender (percentages)}

\begin{tabular}{|c|c|c|c|c|c|c|c|}
\hline \multirow[t]{2}{*}{ Conditions in facilities } & \multirow[t]{2}{*}{ All students $(n=122)$} & \multicolumn{3}{|c|}{ Training institution } & \multicolumn{3}{|c|}{ Gender } \\
\hline & & University $(n=81)$ & $\operatorname{RHSC}(n=41)$ & $P$ & Male $(n=88)$ & Female $(n=34)$ & $P$ \\
\hline \multicolumn{8}{|l|}{ Classroom instruction and resources } \\
\hline Classroom resources are available and appropriate & 26.2 & 27.2 & 24.4 & 0.851 & 25.0 & 29.4 & 0.712 \\
\hline Instructors are effective in facilitating learning & 50.0 & 42.0 & 65.9 & 0.218 & 43.2 & 67.7 & 0.115 \\
\hline Instructors are fair in assessing learning & 48.4 & 34.6 & 75.6 & 0.123 & 45.5 & 55.9 & 0.418 \\
\hline \multicolumn{8}{|l|}{ Skills lab } \\
\hline Number of skills lab assistants is adequate & 4.9 & 2.5 & 9.8 & 0.248 & 6.8 & 0.0 & 0.375 \\
\hline Skills lab resources are available and appropriate & 9.0 & 8.6 & 9.8 & 0.881 & 10.2 & 5.9 & 0.504 \\
\hline Skills lab assistants are effective for learning & 9.0 & 6.2 & 14.6 & 0.090 & 11.4 & 2.9 & 0.238 \\
\hline \multicolumn{8}{|l|}{ Clinical practicum } \\
\hline Practicum sites are conducive to learning & 38.5 & 37.0 & 41.5 & 0.887 & 34.1 & 50.0 & 0.498 \\
\hline Preceptors are available at practicum sites & 72.1 & 63.0 & 90.2 & 0.011 & 68.2 & 82.4 & 0.193 \\
\hline $\begin{array}{l}\text { Among students who said that preceptors were } \\
\text { available at practicum sites }\end{array}$ & $n=87$ & $n=51$ & $n=36$ & & $n=59$ & $n=28$ & \\
\hline Preceptors are adequate & 35.6 & 31.4 & 41.7 & 0.528 & 35.6 & 35.7 & 0.989 \\
\hline Preceptors' support is adequate at the scheduled time & 47.1 & 38.8 & 59.5 & 0.376 & 44.1 & 55.6 & 0.520 \\
\hline Practical experience is sufficient & 55.7 & 58.0 & 51.2 & 0.515 & 53.4 & 61.8 & 0.382 \\
\hline
\end{tabular}

RHSC=Regional health science college

RHSC students were significantly more likely than university students to believe that preceptors were available at practicum sites $(90.2 \%$ versus $63.0 \%, P=0.011)$.

\section{Endotracheal intubation}

The Ethiopian curriculum requires anesthesia students to perform a minimum of 200 endotracheal intubations at clinical practicum sites. Only $57.4 \%$ of graduates reported meeting that standard [Table 4]. University graduates were more likely than RHSC graduates to do so ( $76.5 \%$ versus $19.5 \%$, $P=0.018)$.

\section{Factors associated with student competency}

Bivariate and multivariate linear regression models used predictors selected based on trends observed in the preliminary data analysis and discussions among the research team. The bivariate logistic regression found that the mean skills score was significantly associated with student's gender and type of training institution [Table 5]. These two factors remained significant in a multivariate linear regression: Competence was associated with being male and attending a university training program.

\section{Discussion}

Task-shifting of surgical care to mid-level providers may be a safe and sustainable way to address the surgical workforce shortage in low resource settings ${ }^{[20]}$ and has been used in a number of countries. ${ }^{[21]}$ Countries have focused on accelerating the production of mid-level cadres, including anesthetists. Training mid-level workers features prominently in national workforce plans in countries such as Zambia, Lesotho, 


\begin{tabular}{|c|c|c|c|c|c|c|c|}
\hline \multicolumn{8}{|c|}{$\begin{array}{l}\text { Table 4: Endotracheal intubations performed by students, by } \\
\text { training institution and gender (percentages) }\end{array}$} \\
\hline \multirow{2}{*}{$\begin{array}{l}\text { Number of } \\
\text { procedures }\end{array}$} & \multicolumn{4}{|c|}{ Training institution } & \multicolumn{3}{|c|}{ Gender } \\
\hline & $\begin{array}{l}\text { All students } \\
\quad(n=122)\end{array}$ & $\begin{array}{l}\text { University } \\
(n=81)\end{array}$ & $\begin{array}{l}\text { RHSC } \\
(n=41)\end{array}$ & $P$ & $\begin{array}{c}\text { Male } \\
(n=88)\end{array}$ & $\begin{array}{l}\text { Female } \\
(n=34)\end{array}$ & $P$ \\
\hline$<200$ & 42.6 & 23.5 & 80.5 & 0.018 & 44.3 & 38.2 & 0.701 \\
\hline 200 & 57.4 & 76.5 & 19.5 & & 55.7 & 61.8 & \\
\hline
\end{tabular}

RHSC=Regional health science college

Table 5: Association between mean skills seore and predictors

\begin{tabular}{|c|c|c|c|c|}
\hline \multirow{2}{*}{$\begin{array}{l}\text { Predictors } \\
\text { (outcome=mean } \\
\text { skills scores) }\end{array}$} & \multicolumn{2}{|l|}{$\begin{array}{l}\text { Bivariate linear } \\
\text { regressions }\end{array}$} & \multicolumn{2}{|c|}{$\begin{array}{l}\text { Multivariate linear } \\
\text { regression }\end{array}$} \\
\hline & $\begin{array}{l}\text { Coefficients } \\
(95 \% \mathrm{Cl})\end{array}$ & $P$ & $\begin{array}{l}\text { Coefficients } \\
(95 \% \mathrm{Cl})\end{array}$ & $P$ \\
\hline Gender (ref: female) & - & - & - & - \\
\hline Male & $0.063(0.019-0.107)$ & 0.014 & $0.076(0.007-0.145)$ & 0.037 \\
\hline Age in years & $0.010(0.025-0.004)$ & 0.117 & $0.003(0.013-0.008)$ & 0.555 \\
\hline $\begin{array}{l}\text { Training institution } \\
\text { (ref: RHSC) }\end{array}$ & - & - & - & - \\
\hline University & $0.090(0.019-0.162)$ & 0.023 & $0.096(0.042-0.151)$ & 0.006 \\
\hline \multicolumn{5}{|l|}{$\begin{array}{l}\text { Number of ETTls } \\
\text { performed (ref: <200) }\end{array}$} \\
\hline$>200$ procedures & $0.037(0.041-0.115)$ & 0.281 & $0.014(0.043-0.014)$ & 0.256 \\
\hline
\end{tabular}

and Ghana; ${ }^{[22]}$ in Tanzania ${ }^{[23]}$ and Mozambique, ${ }^{[24]}$ mid-level professionals successfully provide major surgery.

The effort to rapidly increase the number of anesthetists in Ethiopia by expanding the number and size of training institutions is a tremendous achievement, but the mean score of $61.5 \%$ on the OSCE suggests that some graduates may not be fully prepared to safely provide services upon deployment. This raises questions about the adequacy of the training programs and their learner assessment methods, as study participants had already passed their institutional examinations. Although comparable studies of anesthesia training programs in other countries are not available, research on another mid-level cadre-nurses-suggests that this problem is not limited to Ethiopia. Studies in South Africa and the United Kingdom have identified deficits in the competence of newly qualified nurses. ${ }^{[25-27]}$

Student performance was not uniformly low across the skills assessed. The mean score of $79.5 \%$ for lumbar puncture for spinal anesthesia is important for Ethiopia, where three-quarters of the population resides in rural areas ${ }^{[28]}$ with limited access to facilities providing general anesthesia. Similarly, the mean score for neonatal resuscitation (74.4\%) suggests that students can effectively address challenges when they encounter birth asphyxia. It is also encouraging that the mean score for endotracheal intubation was $72.8 \%$, even though only $57.4 \%$ of students had performed 200 or more endotracheal intubations.
Of concern are low mean scores for routine anesthesia machine check (36.9\%) and preoperative screening assessment (44.8\%), both of which are essential for patient safety. ${ }^{[29,30]}$ Training institutions should consider curricula revisions, design of teaching materials, additional credit hours, more practice time in adequately staffed and equipped simulation labs, and increased caseloads and case mix during clinical practice rotations, all of which can strengthen student performance. ${ }^{[8,31,32]}$

Verification that students have mastered basic skills before deployment is important, as is ensuring that they receive ongoing support when employed. Strategies include establishment of a national licensing exam; ${ }^{[33]}$ standardization, validation, and oversight of existing assessments; supportive supervision post-deployment; and in-service training. In Nepal, onsite coaching for anesthesia assistants has proven effective in strengthening their skills. ${ }^{[34]}$

\section{Factors affecting student performance}

Female graduates consistently performed more poorly on the OSCE than male counterparts. These results differ from previous studies of medical and physiotherapy students in the United Kingdom, ${ }^{[35,36]}$ medical students in the United States, ${ }^{[37,38]}$ nursing students in Pakistan, ${ }^{[39]}$ and anesthesia students in Saudi Arabia, ${ }^{[40]}$ all of which found that women tend to perform better than men on clinical skills assessments. Our findings call for targeted efforts to support female students during training, ${ }^{[41]}$ including life skills training, safe campus environments, peer-to-peer coaching, and study support.

University graduates outperformed RHSC graduates on most competencies. Limited clinical practice opportunities and inadequate teaching staff at RHSCs likely play a role, highlighting the need for strengthened infrastructure and qualified instructors at RHSCs. Other options include twinning with nearby universities and RHSCs to mentor faculty and share best practices. RHSCs should also consider ways to increase student exposure to cases, such as weekend and night rotations or collaborating with nearby health facilities. It should be noted, however, that this study did not investigate other potentially important factors, such as program length (one year at RHSCs versus four years at universities) and the nature of the student body (high school graduates seeking a baccalaureate degree versus nurses seeking specialty training).

\section{Student perceptions of adequacy of learning environment}

Student perceptions of their learning environment are associated with learning outcomes and attitudes toward studying ${ }^{[42]}$ and can help identify areas needing improvement. ${ }^{[43]}$ It is clear that substantial investment is needed in skills labs, clinical practice sites, and the teaching skills of faculty and preceptors. 


\section{Strengths and limitations}

This study provides insights into the quality of anesthesia higher education in a low-resource setting. The OSCE approach is a reasonably reliable, valid, objective, and practical method of assessing different competency domains (knowledge, skills, and attitudes) during a single assessment, ${ }^{[19,44-46]}$ However, it is possible that there was an examination bias; we did not examine the gender breakdown of the examiners relative to the scores given to women. In addition, the structured interview tools were not pilot-tested and validated, although inconsistencies and errors were identified and corrected during data collectors' training. We were unable to include all eligible training institutions and students in the study, which may limit our ability to generalize the findings to the national level. However, the four RHSCs excluded from the study because of earlier than expected graduations are not materially different from the two RHSCs included in the sample. It is impossible to know whether the competency of the 31 students who did not participate differed from those observed.

\section{Conclusions}

Findings suggest that rapid expansion of higher education programs has not solved the problem of providing safe anesthesia services in Ethiopia, because of limited teaching and learning infrastructure and minimal opportunities for clinical practice. Literature on the link between rapid expansion of higher education institutions and competency of students is not available. However, this study suggests that the emphasis on increasing the number of anesthetists may come at the expense of their competency.

These findings have important implications for policymakers not just in Ethiopia, but across all countries that are struggling to rapidly expand their health workforce. As countries design and implement approaches to scale up higher education, they should prioritize measures that ensure graduates master required skills and can offer safe services. This requires a focus on the quality of training and assessment of learners.

Graduates entering the workforce should also be provided with targeted on-the-job mentoring, supportive supervision, and in-service training to improve and maintain their competence. Further research can help identify factors that are associated with the performance of anesthesia graduates in real world clinical settings, rather than a simulated test environment, and test interventions targeted to underperforming students and institutions.

\section{Acknowledgment}

This study was made possible by the generous support of the American people through the United States Agency for International Development (USAID) under the Cooperative Agreement AID-663-A-12-00008. The contents are the responsibility of Jhpiego and do not necessarily reflect the views of USAID or the United States Government.

We are grateful to the universities and regional health science colleges that allowed us to conduct this study. We acknowledge Tegbar Yigzaw and Firew Ayalew for their contributions to the conceptualization, design, and analysis of data. We would like to thank Tom Bashford (University of Cambridge) and Catherine Carr (Jhpiego USA) for providing critical reviews of the manuscript. We acknowledge Gayane Yenokyan (Johns Hopkins University) and Mark Emerson (Johns Hopkins University) for their support in data analysis.

\section{Financial support and sponsorship}

Research funded by the United States Agency for International Development (USAID) under the Cooperative Agreement AID-663-A-12-00008.

\section{Conflicts of interest}

There are no conflicts of interest.

\section{References}

1. Canas M, Moreno R, Rhodes A, Grounds RM. Patient safety in anesthesia. Minerva Anestesiol 2010;76:753-7.

2. Li G, Warner M, Lang BH, Huang L, Sun LS. Epidemiology of anesthesia-related mortality in the United States, 1999-2005. Anesthesiology 2009;110:759-65.

3. Bainbridge D, Martin J, Arango M, Cheng D; Evidence-based Peri-operative Clinical Outcomes Research (EPiCOR) Group. Perioperative and anaesthetic-related mortality in developed and developing countries: A systematic review and meta-analysis. Lancet 2012;380:1075-81.

4. Enright A. Review article: Safety aspects of anesthesia in under-resourced locations. Can J Anaesth 2013;60:152-8.

5. Hoyler M, Finlayson SR, McClain CD, Meara JG, Hagander L. Shortage of doctors, shortage of data: A review of the global surgery, obstetrics, and anesthesia workforce literature. World J Surg 2014;38:269-80.

6. LeBrun DG, Chackungal S, Chao TE, Knowlton LM, Linden AF, Notrica MR, et al. Prioritizing essential surgery and safe anesthesia for the post-2015 development Agenda: Operative capacities of 78 district hospitals in 7 low- and middle-income countries. Surgery 2014; $155: 365-73$.

7. World Health Organization. Africa health workforce observatory: Human resources for health country profile: Ethiopia. Geneva: World Health Organization; 2010.

8. Chao TE, Burdic M, Ganjawalla K, Derbew M, Keshian C, Meara J, et al. Survey of surgery and anesthesia infrastructure in Ethiopia. World J Surg 2012;36:2545-53.

9. Bashford T. Anaesthesia in Ethiopia: Providers' perspectives on the current state of the service. Trop Doct 2014;44:6-13.

10. Hodges SC, Mijumbi C, Okello M, McCormick BA, Walker IA, Wilson IH. Anaesthesia services in developing countries: Defining the problems. Anaesthesia 2007;62:4-11.

11. Chu K, Rosseel P, Gielis P, Ford N. Surgical task shifting in sub-Saharan Africa. PLoS Med 2009;6:e1000078.

12. Mullan F, Frehywot S. Non-physician clinicians in 47 sub-Saharan African countries. Lancet 2007;370:2158-63. 
13. Zimmerman M, Lee M, Retnaraj S. Non-doctor anaesthesia in Nepal: Developing an essential cadre. Trop Doct 2008;38:148-50.

14. Dubowitz G, Detlefs S, McQueen KA. Global anesthesia workforce crisis: A preliminary survey revealing shortages contributing to undesirable outcomes and unsafe practices. World J Surg 2010;34:438-44.

15. Jochberger S, Ismailova F, Banda D, Mayr VD, Luckner G, Lederer W, et al. A survey of the status of education and research in anaesthesia and intensive care medicine at the University Teaching Hospital in Lusaka, Zambia. Arch Iran Med 2010;13:5-12.

16. Jhpiego Ethiopia. "Strengthening Human Resources for Health (HRH) Program: Baseline Survey Findings"; 2013.

17. International Federation of Nurse Anesthetists (IFNA). Educational standards for preparing nurse anesthetists. IFNA; 1999.

18. Nulty DD, Mitchell ML, Jeffrey CA, Henderson A, Groves M. Best practice guidelines for use of OSCEs: Maximising value for student learning. Nurse Educ Today 2011;31:145-51.

19. Patrício MF, Julião M, Fareleira F, Carneiro AV. Is the OSCE a feasible tool to assess competencies in undergraduate medical education? Med Teach 2013;35:503-14.

20. Beard JH, Oresanya LB, Akoko L, Mwanga A, Mkony CA, Dicker RA. Surgical task-shifting in a low-resource setting: Outcomes after major surgery performed by nonphysician clinicians in Tanzania. World J Surg 2014;38:1398-404.

21. Kruk ME, Wladis A, Mbembati N, Ndao-Brumblay SK, Hsia RY, Galukande $\mathrm{M}$, et al. Human resource and funding constraints for essential surgery in district hospitals in Africa: A retrospective cross-sectional survey. PLoS Med 2010;7:e1000242.

22. Bangdiwala SI, Fonn S, Okoye O, Tollman S. Workforce resources for health in developing countries. Public Health Reviews 2010;32:296-318. Available from: http://www. publichealthreviews. eu/upload/pdf_files/7/17_Workforce.pdf. [Last accessed on 2015 Oct 09].

23. Pereira C, Mbaruku G, Nzabuhakwa C, Bergström S, McCord C. Emergency obstetric surgery by non-physician clinicians in Tanzania. Int J Gynaecol Obstet 2011;114:180-3.

24. Pereira C, Cumbi A, Malalane R, Vaz F, McCord C, Bacci A, et al. Meeting the need for emergency obstetric care in Mozambique: Work performance and histories of medical doctors and assistant medical officers trained for surgery. BJOG 2007;114:1530-3.

25. Clark T, Holmes S. Fit for practice? An exploration of the development of newly qualified nurses using focus groups. Int $\mathrm{J}$ Nurs Stud 2007;44:1210-20.

26. Moeti MR, van Niekerk SE, van Velden CE. Perceptions of the clinical competence of newly registered nurses in the north west province. Curationis 2004;27:72-84.

27. Morolong BG, Chabeli MM. Competence of newly qualified registered nurses from a nursing college. Curationis 2005;28:38-50.

28. Central Statistical Agency [Ethiopia], ICF International. Ethiopia Demographic and Health Survey 2011. Addis Ababa: Central Statistical Agency and ICF International; 2012.

29. Association of Anaesthetists of Great Britain and Ireland (AAGBI), Hartle A, Anderson E, Bythell V, Gemmell L, Jones H, et al. Checking anaesthetic equipment 2012: Association of anaesthetists of Great Britain and Ireland. Anaesthesia 2012;67:660-8.
30. Casey PM, Goepfert AR, Espey EL, Hammoud MM, Kaczmarczyk JM, Katz NT, et al. To the point: Reviews in medical education - the objective structured clinical examination. Am J Obstet Gynecol 2009;200:25-34.

31. Fonjungo PN, Kebede Y, Arneson W, Tefera D, Yimer K, Kinde S, et al. Preservice laboratory education strengthening enhances sustainable laboratory workforce in Ethiopia. Hum Resour Health 2013;11:56.

32. Murray DJ. Current trends in simulation training in anesthesia: A review. Minerva Anestesiol 2011;77:528-33.

33. Boulet J, van Zanten M. Ensuring high-quality patient care: The role of accreditation, licensure, specialty certification and revalidation in medicine. Med Educ 2014;48:75-86.

34. Ross O, Flutter L, Dali L, Rai S, Rai I, Rana R, et al. Anaesthesia Assistant Follow-up and Enhancement Programme, Nepal 2011-2012. Available from: http://www.aagbi.org/sites/default/ files/ROSS, $\% 20$ Oliver\%20-\%20AA\%20FEP\%20report.pdf. [Last retrieved on $2015 \mathrm{Feb} 26]$.

35. Dewhurst NG, McManus C, Mollon J, Dacre JE, Vale AJ. Performance in the MRCP (UK) examination 2003-4: Analysis of pass rates of UK graduates in relation to self-declared ethnicity and gender. BMC Med 2007;5:8.

36. Hammond JA. Assessment of clinical components of physiotherapy undergraduate education: Are there any issues with gender? Physiotherapy 2009;95:266-72.

37. Cuddy MM, Swanson DB, Clauser BE. A multilevel analysis of the relationships between examinee gender and United States medical licensing exam (USMLE) step 2 CK content area performance. Acad Med 2007;82 10 Suppl: S89-93.

38. Craig LB, Smith C, Crow SM, Driver W, Wallace M, Thompson BM. Obstetrics and gynecology clerkship for males and females: Similar curriculum, different outcomes? Med Educ Online 2013;18:21506.

39. Ali PA, Naylor PB. Association between academic and non-academic variables and academic success of diploma nursing students in Pakistan. Nurse Educ Today 2010;30:157-62.

40. Shams T, El-Masry R, Al Wadani H, Amr M. Assessment of current undergraduate anesthesia course in a Saudi University. Saudi J Anaesth 2013;7:122-7.

41. Blanch DC, Hall JA, Roter DL, Frankel RM. Medical student gender and issues of confidence. Patient Educ Couns 2008;72:374-81.

42. Colbert-Getz JM, Kim S, Goode VH, Shochet RB, Wright SM. Assessing medical students' and residents' perceptions of the learning environment: Exploring validity evidence for the interpretation of scores from existing tools. Acad Med 2014;89:1687-93.

43. Brown T, Williams B, McKenna L, Palermo C, McCall L, Roller L, et al. Practice education learning environments: The mismatch between perceived and preferred expectations of undergraduate health science students. Nurse Educ Today 2011;31:e22-8.

44. Barman A. Critiques on the objective structured clinical examination. Ann Acad Med Singapore 2005;34:478-82.

45. Harden RM, Stevenson M, Downie WW, Wilson GM. Assessment of clinical competence using objective structured examination. $\mathrm{Br}$ Med J 1975;1:447-51.

46. World Health Organization, JHPIEGO. Effective Teaching: A Guide for Educating Healthcare Providers. Reference Manual. Geneva: World Health Organization; 2005. 